\title{
Predictors of poor neonatal outcomes in fetuses diagnosed with congenital urinary tract anomalies
}

\author{
Sonja Pop-Trajkovic Dinic, Radomir Zivadinovic, Milan Stefanovic, \\ Milan Trenkic, Jelena Milosevic, Dejan Mitic \\ Clinic for Gynecology and Obstetrics, Clinical Center of Niš, Serbia
}

\begin{abstract}
Objectives: Urinary tract anomalies account for approximately one-quarter of all antenatally detected anomalies. The aim of this study was to identify factors associated with severe adverse neonatal outcomes of a prenatally diagnosed urinary tract anomaly.

Material and methods: A retrospective-prospective study included 101 pregnant women with prenatally diagnosed fetal urinary tract anomalies presented to the Council for Fetal Anomalies. Prenatal diagnoses were compared with autopsy findings in cases of terminated pregnancy or with clinical and operative findings of the infants.

Results: The mortality rate in the group of patients with fetal obstructive uropathy (60 patients) was $10 \%$ and in the group of patients with fetal multicystic dysplastic kidney (38 patients) $15.7 \%$. Surgery was performed on $53.4 \%$ of the children, whereas more than half of the operations involved resolving associated urinary tract anomalies. Postoperative renal function deterioration occurred in $19 \%$ of the children.

Conclusions: The prognosis of renal function in obstructive uropathies is excellent if oligoamnios does not develop prenatally and in case of timely provided surgical care is provided postnatally. The finding of the bilateral multicystic dysplastic kidney is associated with poor prognosis. The prognosis in fetal unilateral multicystic dysplastic kidney depends primarily on the condition of the contralateral kidney and the existence of associated anomalies.
\end{abstract}

Key words: fetus; congenital; urinary tract; anomalies; outcome

Ginekologia Polska 2021; 92, 9: 607-610

\section{INTRODUCTION}

According to literature data, urinary tract anomalies account for slightly less than one-quarter of all antenatally detected anomalies. As many as $60 \%$ of all urinary tract anomalies account for obstructive uropathies and close to $30 \%$ for multicystic dysplastic kidney [1, 2]. In obstructive uropathies, antenatal sonography detects not only an anomaly but also the location of the obstruction occurrence, whereas we can also evaluate renal function by biochemical analysis of fetal urine obtained by the bladder puncture. Multicystic dysplastic kidney rarely causes diagnostic dilemmas and is detected easily by a routine prenatal sonographic examination. The kidney itself is enormously enlarged and is the most common cause of sonographic findings of cystic masses in the fetal abdomen, whereas its function is less than $10 \%$ [3].
Numerous studies have examined the incidence of fetal urinary tract anomalies, genetics, etiopathogenesis, association with other abnormalities, and surgical procedures conducted on children after birth [4-8]; however, questions remain about prenatally identified factors associated with adverse perinatal-neonatal outcomes.

The objectives of this study were to characterise clinical outcomes of a prenatally diagnosed urinary tract anomaly and to assess prenatal variables associated with the adverse outcome or favourable prognosis for the purpose of adequate counselling of patients.

\section{MATERIAL AND METHODS}

A retrospective-prospective study included pregnant women with a congenital fetal urinary tract anomaly pre-

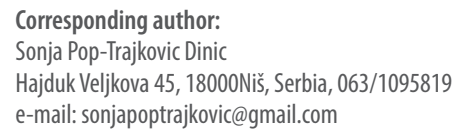

This article is available in open access under Creative Common Attribution-Non-Commercial-No Derivatives 4.0 International (CC BY-NC-ND 4.0) license, allowing to download articles and share them with others as long as they credit the authors and the publisher, but without permission to change them in any way or use them commercially. 
sented to the Council for Fetal Anomalies at the Institute of Gynaecology and Obstetrics, Clinical Centre of Serbia, and University Children's Hospital, Belgrade within a three-year period. Prenatal evaluation of fetal urinary tract included expert fetal ultrasound examination with fetal echocardiography and, depending on the assessment of the Council team, additional diagnostics such as magnetic resonance imaging, amniocentesis with karyotyping, and fetal urine analysis.

Patients diagnosed with a fetal anomaly incompatible with life or anomalies with poor postnatal outcomes were advised to terminate the pregnancy, whereas the proposals for termination were presented to the Ethics Committee. Patients having a favourable prognosis were referred to their gynaecologists for pregnancy monitoring and completion according to obstetric indications. Postnatal evaluation of the infant urinary tract (ultrasonographic examination, micturating cystourethrography, and radioisotope imaging techniques: MAG-3, DMSA, DTPA), and certain interventions (one or two) if necessary, were performed at the University Children's Hospital. Data used in this study were obtained based on prenatal diagnoses, autopsy findings (in case of lethal outcomes), and clinical and operative findings of the infants.

\section{RESULTS}

Within a three-year period, 101 pregnant women with a suspected fetal urinary tract anomaly were referred to the Council For Fatal Anomalies. Fetal urinary tract dilation was diagnosed prenatally in 60 patients (59.4\%), whereas the diagnosis of fetal multicystic dysplastic kidney was established in 38 patients (37.6\%). The remaining patients were diagnosed with dysfunctions in the number, fusion, and localization of the kidneys and were not included in the study.

\section{Mortality}

In the group of patients with an obstructive urinary tract anomaly, the pregnancy was terminated in six patients (10\%). After the obtained approval from the Ethics Committee, the termination was performed in two cases of bilateral hydronephrosis, severe oligoamnios, and poor results of the fetal urine analyses indicating the existence of fetal renal insufficiency during early gestation and in four cases of a sonographic finding of megacystis and oligoamnios. The average length of gestation before the pregnancy termination was 26 weeks. The fetal sex was male in all cases.

In patients diagnosed with fetal multicystic dysplastic kidney, the pregnancy was terminated in four patients (10.5\%) after obtaining the approval from the Ethics Committee, whereas in two cases (5.2\%) child deaths occurred after birth. Excluding two fetuses with multicystic dysplastic kidney confirmed by autopsy findings, in cases of unilateral multicystic dysplasia, the autopsy revealed associated urinary tract anomalies and extrarenal anomalies (Tab. 1).

\section{Surviving children with urinary tract anomalies}

Of the 54 patients with a prenatally detected obstructive anomaly of the fetal urinary tract, three were misdiagnosed as verified postnatally. Isolated unilateral or bilateral hydronephrosis, a slightly higher number of the bilateral one, was detected in 30 children (55\%). The remaining children had associated urinary tract anomalies. The obstruction cause, the number of operated children, and the number of children with renal function deterioration are shown in Table 2.

The urinary tract of 32 surviving children with a multicystic dysplastic kidney was evaluated postnatally. Radioisotope examination revealed that the kidney altered due to multicystic dysplasia was either entirely dysfunctional or its function was less than $5 \%$.

Ultrasound examination and micturating cystourethrography revealed one or more associated urinary tract anomalies in 27 (84.3\%) children (Tab. 3). Surgery was performed on $28(73.6 \%)$ children. In seven (17\%) children, renal function deterioration was observed during postoperative follow-up. The remaining children required no interventions and undergo regular check-ups.

\section{DISCUSSION}

In the group of patients with congenital fetal obstructive uropathy, the highest number of terminated pregnancies was in fetuses with pronounced megacystis and reduced amniotic fluid volume. Reduced amniotic fluid in early gestation was the main poor prognostic factor in obstructive uropathy. The literature data also indicated high mortality rates in fetuses with this anomaly [9]. In our study, all preg-

Table 1. Fetal autopsy findings (associated renal and extrarenal anomalies) in four cases of terminated pregnancies

\begin{tabular}{|l|c|c|}
\hline & & \multicolumn{2}{|c|}{ Autopsy findings } \\
\hline Prenatal diagnosis & Associated urinary tract anomalies & Extrarenal anomalies \\
\hline Multicystic left kidney and right kidney anomaly & Agenesis of the right kidney & Anal and vaginal atresia \\
\hline Multicystic right kidney and no amniotic fluid & Hypoplastic bladder and left kidney & Hypoplastic penis \\
\hline Multicystic left kidney and no amniotic fluid & Agenesis of the right kidney & Cleft lip and palate \\
\hline Multicystic left kidney and polycistic right kidney & Right kidney dysplasia & Hypoplastic genitalia \\
\hline
\end{tabular}




\begin{tabular}{|c|c|c|c|c|}
\hline Postnatal diagnosis & Cause? & No of children & $\begin{array}{c}\text { No of the children } \\
\text { who underwent } \\
\text { surgery }\end{array}$ & $\begin{array}{l}\text { No of children with the } \\
\text { postoperative renal function } \\
\text { deterioration }\end{array}$ \\
\hline $\begin{array}{l}\text { Isolated uni/bilateral } \\
\text { hydronephrosis }\end{array}$ & $\begin{array}{l}\text { - Stenosis of the pyeloureteral junction } \\
\text { - VUR }\end{array}$ & $30(55.5 \%)$ & $11(36.6 \%)$ & $1(3.33 \%)$ \\
\hline $\begin{array}{l}\text { Hydronephrosis } \\
\text { associated with } \\
\text { uni/bilateral megaureter }\end{array}$ & $\begin{array}{l}\text { - Stenosis of the pyeloureteral junction } \\
\text { - Stenosis of the vesicoureteric junction } \\
\text { - Congenital megaureter } \\
\text { - Ureter duplex } \\
\text { - Posterior urethral valve } \\
\text { - VUR }\end{array}$ & $16(29.6 \%)$ & $10(62.5 \%)$ & $2(12.5 \%)$ \\
\hline Megacystis & $\begin{array}{l}\text { - Posterior urethral valve } \\
\text { - Narrowed urethra }\end{array}$ & 5 (9.25\%) & $5(100 \%)$ & $2(40 \%)$ \\
\hline
\end{tabular}

VUR - vesicoureteral reflux

Table 3. Anomalies of the contralateral kidney, the ipsilateral kidney, and the lower urinary tract in infants prenatally diagnosed with multicystic dysplastic kidney

\begin{tabular}{|l|c|c|c|}
\hline Type of anomaly & $\begin{array}{c}\text { Contralateral kidney } \\
\text { (no of anomalies) }\end{array}$ & $\begin{array}{c}\text { Ipsilateral kidney } \\
\text { (no of anomalies) }\end{array}$ & $\begin{array}{c}\text { Lower urinary tract } \\
\text { (no of anomalies) }\end{array}$ \\
\hline Hydronephrosis & 3 & & \\
\hline Pyelectasis & 4 & 2 & 2 \\
\hline Megaureter & 1 & 1 & 4 \\
\hline Ectopic ureter & 2 & & 1 \\
\hline Ureterocele & 2 & & \\
\hline Posterior urethral valve & & 2 & 5 \\
\hline Urethral stenosis & 8 & 7 & \\
\hline VUR & 20 & & \\
\hline Total & & & \\
\hline
\end{tabular}

VUR - vesicoureteral reflux

nancies were terminated before the fetuses were capable of independent life.

The outcome of surviving children with obstructive uropathy was relatively favourable. The results of our study showed that isolated unilateral hydronephrosis is a benign condition, whereas the possibility of spontaneous resolution is very high, especially if the pelvis diameter prenatally at 32 weeks was less than $15 \mathrm{~mm}$. Previous studies have demonstrated similar results [10].

Vesicoureteral reflux (VUR) was responsible for approximately $12 \%$ of dilatation detected antenatally, similarly to the percentage reported in the literature (15\%) [11].

A high number of interventions were required in children with a prenatal diagnosis of hydronephrosis and megaureter (close to 60\%), primarily in those with postnatally detected pyelo-ureteral junction stenosis.

The percentage of interventions was also high in the group of children with a prenatally diagnosed bilateral hy- dronephrosis and postnatally confirmed VUR with various degrees of severity (close to $30 \%$ ). Since VUR predisposes patients to urinary tract infection, all children in this study with the dilatation of pyelon greater than $10 \mathrm{~mm}$ were postnatally treated with low dose antibiotics terapy in the first three months of life [12]. The highest number of interventions were required in children with megacystis caused by a posterior urethral valve $[13,14]$.

In general, in the group of children with a dilated uropathy, renal function deterioration occurred only in cases of pronounced bilateral hydronephrosis or pronounced megacystis with the development of oligoamnios requiring labour induction immediately upon achieving fetal lung maturation.

Regarding fetal multicystic dysplastic kidney, our study showed the highest mortality rate in cases of bilateral dysplasia, prenatally diagnosed extrarenal anomalies, and oligoamnios. In comparison to prior research results concerning anomalies of the contralateral kidney, we obtained 
similar data. Namely, the contralateral kidney anomalies were found in approximately $32 \%$ of children, similar to data from previous studies (21-35\%) $[15,16]$.

VUR was diagnosed in $22 \%$ of children. Data from previous research studies indicate a VUR range of 4.8 to $28 \%$ [17].

The most frequent anomalies of the ipsilateral side include megaureter, ectopic ureter and VUR, whereas the lower urinary tract anomalies were present in $13.2 \%$ of children, slightly higher than reported in previous studies (6\%) [18].

Despite conflicting opinions on the application of cystoscopy and nephrectomy in this group cystoscopy revealed an ectopic ureter in $10 \%$ of children, whereas colposcopy detected an imperforate hymen and an ectopic ureter with the opening located in the vagina in one girl. The outcome of operated children was generally favourable. Nephrectomy or partial nephrectomy was required in 13 out of 28 children, whereas in other children in this group 28 interventions were performed to resolve the anomalies of the contralateral kidney and the lower urinary tract [19-21]. The remaining children required no interventions and undergo regular check-ups.

\section{CONCLUSIONS}

The prognosis of renal function in obstructive uropathies is excellent if oligoamnios does not develop prenatally and in case of timely provided postnatal surgical care. The findings of both bilateral and unilateral MCKD and oligoamnios are associated with poor prognosis. Isolated unilateral MCKD requires serial ultrasound examinations both pre and postnatally since the prognosis depends primarily on the condition of the contralateral kidney and the severity of associated anomalies.

\section{Conflict of interest}

None.

\section{REFERENCES}

1. Li ZY, Chen YM, Qiu LQ, et al. Prevalence, types, and malformations in congenital anomalies of the kidney and urinary tract in newborns: a retrospective hospital-based study. Ital J Pediatr. 2019; 45(1): 50, doi: 10.1186/s13052-019-0635-9, indexed in Pubmed: 30999930.

2. Postoev VA, Grjibovski AM, Kovalenko AA, et al. Congenital anomalies of the kidney and the urinary tract: A murmansk county birth registry study. Birth Defects Res A Clin Mol Teratol. 2016; 106(3): 185-193, doi: 10.1002/bdra.23475, indexed in Pubmed: 26833755.

3. Dias T, Sairam S, Kumarasiri S. Ultrasound diagnosis of fetal renal abnormalities. Best Pract Res Clin Obstet Gynaecol. 2014; 28(3): 403-415, doi: 10.1016/j.bpobgyn.2014.01.009, indexed in Pubmed: 24524801.

4. Capone VP, Morello W, Taroni F, et al. Genetics of Congenital Anomalies of the Kidney and Urinary Tract: The Current State of Play. Int J Mol
Sci. 2017; 18(4), doi: 10.3390/ijms18040796, indexed in Pubmed: 28398236.

5. Lei TY, Fu F, Li Ru, et al. Whole-exome sequencing for prenatal diagnosis of fetuses with congenital anomalies of the kidney and urinary tract. Nephrol Dial Transplant. 2017; 32(10): 1665-1675, doi: 10.1093/ndt/gfx031, indexed in Pubmed: 28387813.

6. Miao $\mathrm{Q}$, Shen $\mathrm{Q}, \mathrm{Xu} \mathrm{H}$, et al. [Etiological analysis of 264 cases with chronic kidney disease stage 2 to 5 in children]. Zhonghua Er Ke Za Zhi. 2015; 53(9): 665-669, indexed in Pubmed: 26757966.

7. Jiang Y, Shen Y, Lau KK. Survey of chronic haemodialysis in children between 2007 and 2012 in China. Nephrology (Carlton). 2014; 19(7): 375-378, doi: 10.1111/nep.12229, indexed in Pubmed: 24629142.

8. dos Santos Junior AC, de Miranda DM, Simões e Silva AC. Congenital anomalies of the kidney and urinary tract: an embryogenetic review. Birth Defects Res C Embryo Today. 2014; 102(4): 374-381, doi: 10.1002/bdrc.21084, indexed in Pubmed: 25420794.

9. Chen L, Guan J, Gu H, et al. Outcomes in fetuses diagnosed with megacystis: Systematic review and meta-analysis. Eur J Obstet Gynecol Reprod Biol. 2019; 233: 120-126, doi: 10.1016/j.ejogrb.2018.12.007, indexed in Pubmed: 30594021.

10. Babu R, Sai V. Postnatal outcome of fetal hydronephrosis: implications for prenatal counselling. Indian J Urol. 2010; 26(1):60-62, doi: 10.4103/09701591.60446, indexed in Pubmed: 20535287.

11. Zhang T, Wu S. Prenatal ultrasound diagnosis of 1 case of vesicoureteral reflux. Quant Imaging Med Surg. 2016; 6(3): 320-322, doi: 10.21037/qims.2015.08.07, indexed in Pubmed: 27429918.

12. Sharma G. Postnatal management of antenatally detected hydronephrosis. World Journal of Clinical Urology. 2014; 3(3): 283, doi: 10.5410/wjcu. v3.i3.283.

13. Marzuillo P, Guarino S, Grandone A, et al. Outcomes of a Cohort of Prenatally Diagnosed and Early Enrolled Patients with Congenital Solitary Functioning Kidney. J Urol. 2017; 198(5): 1153-1158, doi: 10.1016/j. juro.2017.05.076, indexed in Pubmed: 28554812.

14. Ramanathan $S$, Kumar D, Khanna M, et al. Multi-modality imaging review of congenital abnormalities of kidney and upper urinary tract. World J Radiol. 2016; 8(2): 132-141, doi: 10.4329/wjr.v8.i2.132, indexed in Pubmed: 26981222.

15. Ralli M, Agarwal S, Badhe B, et al. Unilateral multicystic dysplastic kidney with ipsilateral grade $V$ vesicoureteral reflux: $A$ case report of a rare association. Medical Journal of Dr. D.Y. Patil University. 2017; 10(5): 479, doi: 10.4103/0975-2870.218185.

16. Stoll C, Dott B, AlembikY, et al. Associated nonurinary congenital anomalies among infants with congenital anomalies of kidney and urinary tract (CAKUT). Eur J Med Genet. 2014; 57(7): 322-328, doi: 10.1016/j. ejmg.2014.04.014, indexed in Pubmed: 24821302.

17. Balasundaram $\mathrm{M}, \mathrm{Chock} \mathrm{VY}, \mathrm{Wu} \mathrm{HY}$, et al. Predictors of poor neonatal outcomes in prenatally diagnosed multicystic dysplastic kidney disease. J Perinatol. 2018; 38(6): 658-664, doi: 10.1038/s41372-018-0093-z, indexed in Pubmed: 29572458.

18. Psooy K. Multicystisc displastic kidney in the neonate: The role of the urologist. Can Urol Assoc J. 2016; 10(1-2): 18-24.

19. Andrés-Jensen L, Jørgensen FS, Thorup J, et al. The outcome of antenatal ultrasound diagnosed anomalies of the kidney and urinary tract in a large Danish birth cohort. Arch Dis Child. 2016; 101(9): 819-824, doi: 10.1136/archdischild-2015-309784, indexed in Pubmed: 27217581.

20. Nef $S$, Neuhaus TJ, Spartà $G$, et al. Outcome after prenatal diagnosis of congenital anomalies of the kidney and urinary tract. Eur J Pediatr. 2016; 175(5): 667-676, doi: 10.1007/s00431-015-2687-1, indexed in Pubmed: 26805407.

21. Bakker MK, Bergman JEH, Fleurke-Rozema $\mathrm{H}$, et al. Prenatal diagnosis of urinary tract anomalies, a cohort study in the Northern Netherlands. Prenat Diagn. 2018; 38(2): 130-134, doi: 10.1002/pd.5200, indexed in Pubmed: 29240244. 